\title{
Modulation of luteinizing hormone and follicle-stimulating hormone in circulation by interactions between endogenous opioids and oestradiol during the peripubertal period of heifers
}

\author{
M. W. Wolfe*, M. S. Roberson†, T. T. Stumpf $\ddagger$ R. J. Kittok and \\ J. E. Kinder§ \\ Department of Animal Science, University of Nebraska, Lincoln, NE 68583, USA
}

\begin{abstract}
Summary. The aim of this study was to determine whether the decline in oestradiol inhibition of circulating luteinizing hormone ( $\mathrm{LH})$ and follicle-stimulating hormone (FSH) during the peripubertal period of heifers is associated with a change in opioid modulation of LH and FSH secretion. Opioid inhibition of LH secretion was determined by response to administration of the opioid antagonist naloxone. Prepubertal heifers (403 days old) were left as intact controls, ovariectomized or ovariectomized and chronically administered oestradiol. Control heifers were used to determine time of puberty. Three weeks after ovariectomy, four doses of naloxone $\left(0.13-0.75 \mathrm{mg} \mathrm{kg}^{-1}\right.$ body weight) or saline were administered to heifers in the treatment groups in a latin square design (one dose per day). Blood samples were collected at intervals of $10 \mathrm{~min}$ for $2 \mathrm{~h}$ before and $2 \mathrm{~h}$ after administration of naloxone. This procedure was repeated four times at intervals of 3 weeks during the time intact control heifers were attaining puberty. All doses of naloxone induced a similar increase in concentration of serum LH within a bleeding period. During the initial bleeding period (before puberty in control heifers), administration of naloxone induced an increase in $\mathrm{LH}$ concentration, but the response was greater for heifers in the ovariectomized and oestradiol treated than in the ovariectomized group. At the end of the study when control heifers had attained puberty (high concentrations of progesterone indicated corpus luteum function), only heifers in the ovariectomized and oestradiol treated group responded to naloxone. Opioid inhibition of $\mathrm{LH}$ appeared to decline in heifers during the time control heifers were attaining puberty. Heifers in the ovariectomized group responded to naloxone at the time of administration with an increase in FSH, but FSH did not respond to naloxone at any other time. Administration of naloxone did not alter secretion of FSH in ovariectomized heifers. These results suggest that opioid neuropeptides and oestradiol are involved in regulating circulating concentrations of LH and possibly FSH during the peripubertal period. Opioid inhibition of gonadotrophin secretion appeared to decline during the peripubertal period but was still present in ovariectomized heifers treated with oestradiol after the time when age-matched control heifers had attained puberty. We conclude that opioid inhibition is important in regulating LH and FSH in circulation in heifers during the peripubertal period. However, opioids continue to be involved in regulation of circulating concentrations of LH after puberty.
\end{abstract}

Keywords: luteinizing hormone; follicle-stimulating hormone; opioids; oestradiol; heifer

\footnotetext{
${ }^{*}$ Current address: Department of Pharmacology, Case Western Reserve University, Cleveland, OH 44106, USA. †Current address: Department of Physiology and Biophysics, University of Iowa, Iowa City, IA 52242, USA. $\ddagger$ Current address: Department of Animal Science, University of Missouri, Columbia, MO 65211, USA.

$\S$ Reprint requests.
} 


\section{Introduction}

Maturation of the hypothalamo-hypophyseal axis during the peripubertal period is characterized by a progressive increase in secretion of luteinizing hormone (LH) in heifers (Schams et al., 1981; Day et al., 1987). Secretion of gonadotrophins is inhibited by factors originating from the ovaries before puberty. After ovariectomy, secretion of $\mathrm{LH}$ and follicle-stimulating hormone (FSH) is increased in prepubertal heifers, but returns to baseline values if oestradiol is administered (Schillo et al., 1982; Day et al., 1984; Wolfe et al., 1989). However, the ability of oestradiol to suppress LH and FSH secretion is reduced at puberty. Steroid feedback on gonadotrophin secretion has been postulated to be mediated in part by opioid neuropeptides. Inhibition of LH secretion by oestradiol is reversed by administering an opioid antagonist (Whisnant \& Goodman, 1988). Opioids inhibit pulsatile LH secretion in prepubertal ewe lambs (Ebling et al., 1989) and opioid regulation of LH secretion does not change during sexual maturation. Decreases in sensitivity to oestradiol inhibition of LH secretion during sexual maturation are not due to changes in opioid modulation of the putative LH pulse generated in ewe lambs (Ebling et al., 1989). In contrast, opioid inhibition of LH secretion declines as female rats near puberty (Blank et al., 1979; Bhanot \& Wilkinson, 1983a). We hypothesized that oestradiol inhibition of gonadotrophin secretion is mediated via opioid neuropeptides in heifers and that opioid inhibition of $\mathrm{LH}$ secretion declines during the peripubertal period when oestradiol inhibition of gonadotrophin secretion is declining.

\section{Materials and Methods}

\section{Animals and treatments}

Prepubertal heifers ( ${ }_{4}^{1}$ Hereford, $\frac{1}{4}$ Angus, $\frac{1}{4}$ Pinzgauer, $\frac{1}{4}$ Red Angus) were used in the study. The 15 animals were maintained in paddocks and supplemented to allow body weight gains of $0.95 \mathrm{~kg} \mathrm{day}^{-1}$. During collection of blood samples animals were restrained in stanchions to which they had previously been acclimatized. Feed and water were provided ad libitum throughout the sampling period.

\section{Experimental design}

Gonadotrophin secretion was measured before and after various doses of the opioid antagonist naloxone were administered to ovariectomized heifers that had received a sham or oestradiol implant. The experiment was conducted during the time age-matched intact control heifers were in their peripubertal period. Thus, gonadotrophin secretion was evaluated after administration of the opioid neuropeptide antagonist naloxone, when oestradiol was inhibiting (before puberty) or no longer inhibiting (subsequent to puberty) gonadotrophin secretion.

Ten heifers were bilaterally ovariectomized $(403 \pm 2$ days of age) and half received an s.c. polydimethylsiloxane implant $(3.35 \mathrm{~mm}$ i.d. $\times 4.65 \mathrm{~mm}$ o.d. $\times 135 \mathrm{~mm}$; Dow Corning, Midland, MI) filled with oestradiol (Sigma Chemical Co., St Louis, MO) and half received a sham implant of similar size. Implants were administered caudal to the shoulder blade on the day of ovariectomy. All implants were preincubated in alcohol for $2 \mathrm{~h}$ and in water overnight. This preincubation was performed as a precaution to avoid a large release of oestradiol into the blood during the first day after implantation.

Sequential blood samples were collected from the jugular vein via an indweiling cannula. Blood samples were collected from the heifers at intervals of $10 \mathrm{~min}$ for $4 \mathrm{~h}$ starting 3 weeks after ovariectomy when heifers averaged 426 days of age. This sampling frequency was used to characterize fully the response to administration of naloxone. Naloxone (Diosynth, Holland) was administered (i.v.) $2 \mathrm{~h}$ after the initiation of sample collection. Sampling continued for $2 \mathrm{~h}$ after naloxone administration. On the basis of our preliminary studies, all changes that occur owing to a bolus administration of naloxone are detected in the first $2 \mathrm{~h}$. Four doses of naloxone $(0.13,0.25,0.50 \mathrm{and} 0.75 \mathrm{mg}$ $\mathrm{kg}^{-1}$ body weight) were administered to heifers in the two groups in a latin square design with one dose being administered per day. These doses were based on previous research in sheep (Malven et al., 1984; Mathews \& Murdoch, 1984). The low doses were used (lower than previous studies) to discriminate responses between different ages more clearly. Naloxone administration was repeated in heifers treated with oestradiol when heifers were 447 , 468 and 488 days of age. At 516 days of age, both groups of ovariectomized heifers were administered naloxone. Gonadotrophin secretion was therefore evaluated at five different ages in heifers from the ovariectomized and oestradiol treated group. Gonadotrophin secretion was not evaluated in sham implanted heifers at the three intermediate times because a steroid-independent change in gonadotrophin secretion is not observed in heifers during the peripubertal period (Day et al., 1984; Wolfe et al., 1989). 
All blood samples were allowed to clot at room temperature and were subsequently stored at $4^{\circ} \mathrm{C}$. Blood was centrifuged within $24 \mathrm{~h}$ of collection at $1520 \mathrm{~g}$ for $15 \mathrm{~min}$ at $4^{\circ} \mathrm{C}$. Serum was removed and frozen at $-20^{\circ} \mathrm{C}$ until assayed. Sequential blood samples were used to evaluate mean concentrations of LH in serum and patterns of LH in circulation. Serum pools were formed for individual animals at each bleeding period by combining aliquots from all serial samples collected before (pool 1) and after (pool 2) administration of naloxone for each animal. These pools were used to evaluate mean concentrations of FSH and oestradiol.

\section{Control heifers}

Five heifers (matched by age and weight with the ovariectomized heifers) remained intact to monitor time of puberty. Single blood samples were collected two times each week by jugular venepuncture for determination of serum progesterone concentrations. These samples were immediately placed on ice and centrifuged within $24 \mathrm{~h}$. Puberty was defined as the first rise in serum progesterone greater than $1 \mathrm{ng} \mathrm{ml}^{-1}$ of serum for a duration of at least 12 days followed by subsequent luteal phases (rises in progesterone).

\section{Hormone assays}

Concentrations of LH in serum were determined by radioimmunoassay (Adams et al., 1975; Wolfe et al., 1989) using an antiserum against ovine LH (TEA-RaOLH no. 35), highly purified iodinated ovine LH (LER-1056-C2) as labelled hormone, and NIH-LH-B7 as standard. Intra- and interassay coefficients of variation were $3 \cdot 2$ and $15 \%$, respectively. The limit of detection for $\mathrm{LH}$ was $23 \cdot 8 \mathrm{pg} \mathrm{ml}^{-1}$ of serum.

Antiserum made against ovine FSH (JAD-RaOFSH no. 17-6,7,9) and highly purified ovine FSH (LER-1976-A2) as labelled hormone and standard were used in the FSH radioimmunoassay (Acosta et al., 1983; Wolfe et al., 1989). Intra- and interassay coefficients of variation were 2.2 and $2.5 \%$, respectively, and the limit of detection was $550 \mathrm{pg}$ $\mathrm{ml}^{-1}$ of serum.

Concentrations of oestradiol were determined in the pool of serum formed from serial samples collected before administration of naloxone (pool 1). All samples were analysed in a single assay that had an intraassay coefficient of variation of $1.5 \%$ and a limit of detection of $1.25 \mathrm{pg} \mathrm{ml}^{-1}$ of serum (Deaver et al., 1988; Wolfe et al., 1989).

Serum progesterone concentrations were analysed for control heifers using immunoreagents obtained from Serono Diagnostics, Inc. (Norwell, MA) as validated in our laboratory (Wolfe et al., 1989). The intra- and interassay coefficients of variation were 3.5 and $8.8 \%$, respectively. The limit of detection was $200 \mathrm{pg} \mathrm{ml}^{-1}$ of serum.

\section{Statistical analysis}

Mean concentrations of LH were calculated for serial samples collected before and after administration of naloxone for each animal at each bleeding period. The deviation in mean concentration of $\mathrm{LH}$ and FSH subsequent to administration of naloxone was determined (mean gonadotrophin subsequent to naloxone - mean gonadotrophin prior to naloxone) as well as the percentage deviation in LH and FSH after naloxone [(mean gonadotrophin subsequent to naloxone - mean gonadotrophin prior to naloxone/mean gonadotrophin prior to naloxone) $\times 100]$. Response to naloxone was analysed as percentage deviation to adjust for the differences in preinjection concentrations of $\mathrm{LH}$ and FSH. Concentration of gonadotrophin before naloxone administration, deviation and percentage deviation in concentration of gonadotrophin were analysed using the repeated measures analysis procedure of SAS (1985). Two analyses were performed on the data. First, the effect of dose of naloxone and time were analysed in ovariectomized heifers administered oestradiol alone. The effects of dose of naloxone, time and treatment with oestradiol were then analysed using data from the first and last bleeding periods from both groups of ovariectomized heifers.

\section{Results}

\section{Controls}

Mean onset of corpus luteum function (puberty) in control heifers occurred at $465 \pm 12$ days of age (mean \pm SEM). The average age of puberty of heifers in the control group occurred between the second and third times of naloxone administration to heifers from the ovariectomized and oestradiol treated group.

Concentrations of oestradiol in ovariectomized heifers administered sham implants were below the sensitivity of the assay. Mean concentration of oestradiol in ovariectomized heifers administered oestradiol implants was $2 \cdot 5 \pm 0 \cdot 2 \mathrm{pg} \mathrm{ml}^{-1}$ of serum (range $2 \cdot 2$ to $3.2 \mathrm{pg} \mathrm{ml}^{-1}$ ). These concentrations are similar to concentrations observed in intact heifers of similar age in a previous study using the same assay system (Wolfe et al., 1989). 


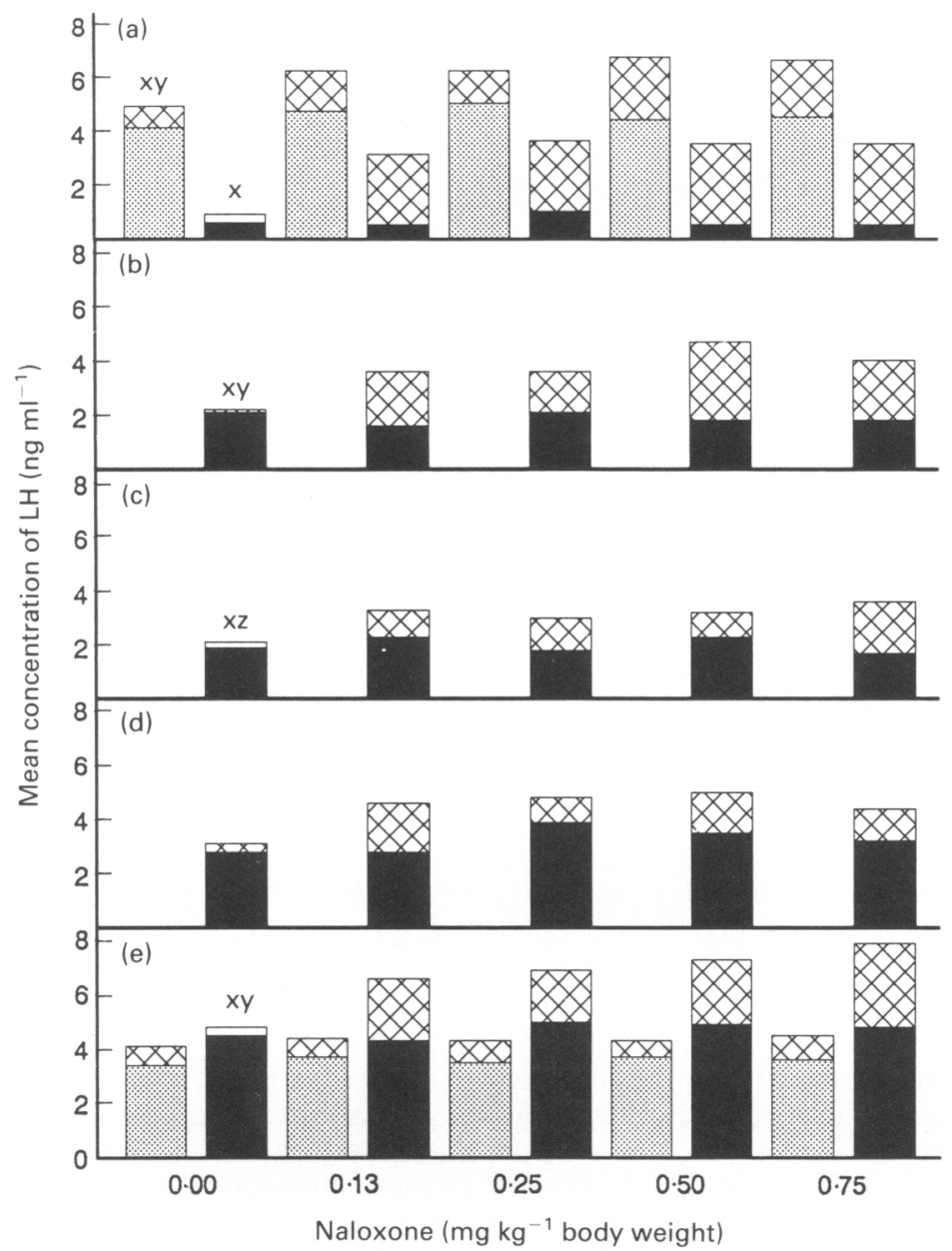

Fig. 1. Mean concentrations of luteinizing hormone (LH) before and after administration of naloxone. Mean concentrations of $\mathrm{LH}$ were determined before administration of naloxone in sham-implanted, ovariectomized heifers (圈) at (a) 426 and (e) 516 days of age and in ovariectomized heifers treated with oestradiol ( $\square$ ) at (a) 426, (b) 447, (c) 468, (d) 488 and (e) 516 days of age. Response to administration of naloxone is depicted as a decrease $(\square)$ or increase ( $\nabla$ ) from pretreatment mean. Pooled standard error for pretreatment mean was 0.3 and $0.2 \mathrm{ng} \mathrm{LH} \mathrm{ml}{ }^{-1}$ of serum for the ovariectomized group at 426 and 516 days of age, respectively. Pooled standard error for means following administration of naloxone were 0.3 and $0.3 \mathrm{ng} \mathrm{LH} \mathrm{ml}{ }^{-1}$ of serum for the ovariectomized group at 426 and 516 days of age, respectively. Pooled standard errors for the ovariectomized and oestradiol-treated group were $0 \cdot 2,0 \cdot 2,0 \cdot 2,0 \cdot 4$ and $0.2 \mathrm{ng} \mathrm{LH}$ $\mathrm{ml}^{-1}$ of serum for the pretreatment means at $426,447,468,488$ and 516 days of age, respectively. After administration of naloxone to the ovariectomized and oestradiol-treated group, pooled standard errors for the means were $0.8,0.6,0.5,0.5$ and $0.3 \mathrm{ng} \mathrm{LH} \mathrm{ml}{ }^{-1}$ of serum at $426,447,468,488$ and 516 days of age, respectively. $x$ : effect of naloxone $(P<0.01), 0.00$ dose versus other doses. $\mathrm{y}$ : cubic effect of naloxone $(P<0.05)$. $\mathrm{z}$ : linear effect of naloxone $(P<0.01)$.

\section{Concentrations of $\mathrm{LH}$}

Mean concentrations of $\mathrm{LH}$ before administration of naloxone (Fig. 1) increased over time $(P<0.01)$ in ovariectomized heifers chronically treated with oestradiol. This resulted in a treatment (oestradiol) by time interaction for mean concentration of LH in circulation before 


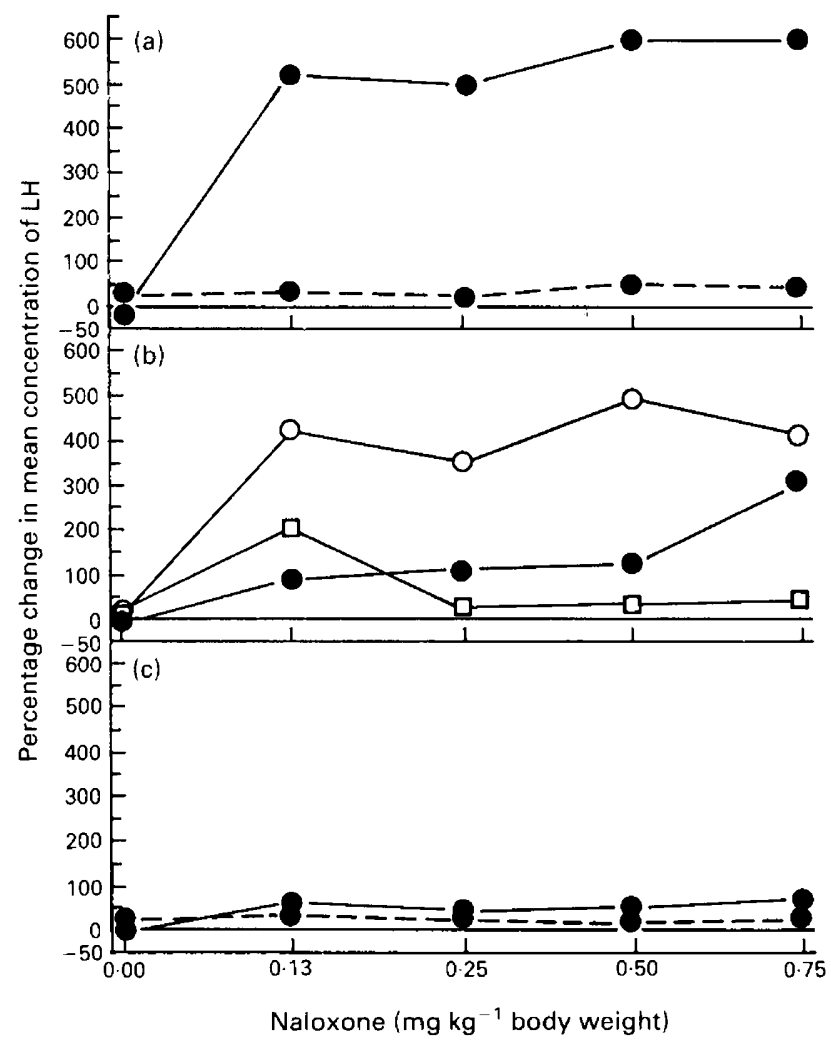

Fig. 2. Percentage change in mean concentrations of luteinizing hormone ( $\mathrm{LH})$ after administration of naloxone. Naloxone was administered to sham implanted ovariectomized heifers (--) at (a) 426 and (c) 516 days of age and to ovariectomized heifers treated with oestradiol ( - ) at (a) 426, (b) 447 (O), 468 (๑), 488 ( $\square$ ) and (c) 516 days of age. Average age at puberty in intact control heifers was 465 days of age.

administration of naloxone $(P<0.01)$. This was due to the increase in $\mathbf{L H}$ in ovariectomized heifers treated with oestradiol and a slight decrease in sham implanted heifers over time.

An overall cubic response pattern was observed after administration of increasing doses of naloxone to heifers treated with oestradiol when all ages at which naloxone was administered were considered $(P<0.01)$. However, the $0.13 \mathrm{mg} \mathrm{kg}^{-1}$ dose of naloxone appeared to be as effective as the $0.75 \mathrm{mg} \mathrm{kg}^{-1}$ dose in eliciting an increase in mean concentration of $\mathrm{LH}$ in heifers treated with oestradiol (Fig. 2).

Naloxone administration resulted in an increase in mean concentrations of $\mathrm{LH}$ in sham implanted heifers at 426 days but not 516 days of age $(P<0 \cdot 01)$. However, the response observed at 426 days in sham implanted heifers was less than that in heifers treated with oestradiol $(P<0.05)$.

Administration of naloxone to ovariectomized heifers treated with oestradiol resulted in an increase in $\mathrm{LH}$ at $426,447,468$ and 516 but not at 488 days of age. Owing to the differences observed between treatment groups and across time with a group in mean concentration of $\mathrm{LH}$ before administration of naloxone, response to naloxone was expressed as percentage deviation in LH. Percentage deviation in LH (Fig. 2) differed between treatments $(P<0.01)$ and across time $(P<0.01)$. The percentage increase in $\mathrm{LH}$ as a result of naloxone administration declined across time $(P<0.05)$ in ovariectomized heifers treated with oestradiol (Fig. 2). In addition, ovariectomized heifers receiving sham implants did not respond to naloxone when expressed as 


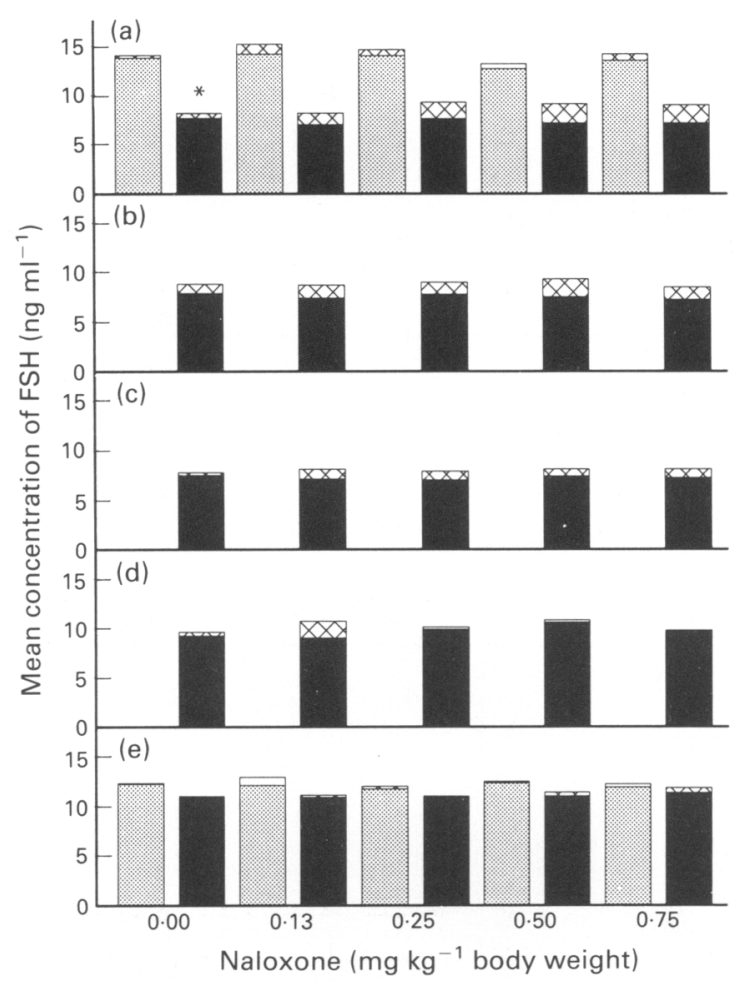

Fig. 3. Mean concentrations of follicle-stimulating hormone (FSH) before and after administration of naloxone. Mean concentration of FSH was determined before administration of naloxone in sham implanted, ovariectomized heifers (圆) at (a) 426 and (e) 516 days of age and in ovariectomized heifers treated with oestradiol ( $($ ) at (a) 426, (b) 447, (c) 468, (d) 488 and (e) 516 days of age. Response to administration of naloxone is shown as a decrease $(\square)$ or increase $(\otimes)$ from pretreatment mean. Pooled standard error for pretreated mean was 0.4 and $0.3 \mathrm{ng} \mathrm{FSH} \mathrm{ml}{ }^{-1}$ of serum for the ovariectomized group at 426 and 516 days of age, respectively. Pooled standard error for means following administration of naloxone was 1.2 and $0.3 \mathrm{ng} \mathrm{LH} \mathrm{ml}^{-1}$ serum for the ovariectomized group at 426 and 516 days of age, respectively. Pooled standard errors for the ovariectomized and oestradiol treated group were $0.3,0 \cdot 3,0 \cdot 3,0.5$ and $0.3 \mathrm{ng} \mathrm{LH} \mathrm{ml}^{-1}$ of serum for the pretreatment means at $426,447,468,488$ and 516 days of age, respectively. After administration of naloxone to the ovariectomized and oestradiol treated group, pooled standard errors for the means were $0 \cdot 4,0 \cdot 3,0 \cdot 3,0 \cdot 6$ and $0.4 \mathrm{ng} \mathrm{LH} \mathrm{ml}^{-1}$ of serum at 426, 447, 468, 488 and 516 days of age, respectively. ${ }^{*}$ Effect of naloxone $(P<0 \cdot 01)$, control versus all doses.

percentage deviation in $\mathbf{L H}$, whereas a response was observed in ovariectomized heifers treated with oestradiol.

\section{Concentrations of FSH}

Mean concentrations of FSH in circulation before administration of naloxone (Fig. 3) increased over time $(P<0.01)$ in ovariectomized heifers treated with oestradiol. Mean concentrations of FSH before administration of naloxone were greater at 426 days of age $(P<0.01)$ in sham implanted heifers than in heifers treated with oestradiol, but were similar at 516 days of age. This resulted in a time by treatment interaction $(P<0.01)$.

Circulating concentrations of FSH were not altered by naloxone at any time in heifers receiving sham implants. The percentage deviation in FSH in ovariectomized heifers administered sham implants was not altered by naloxone during the study. 


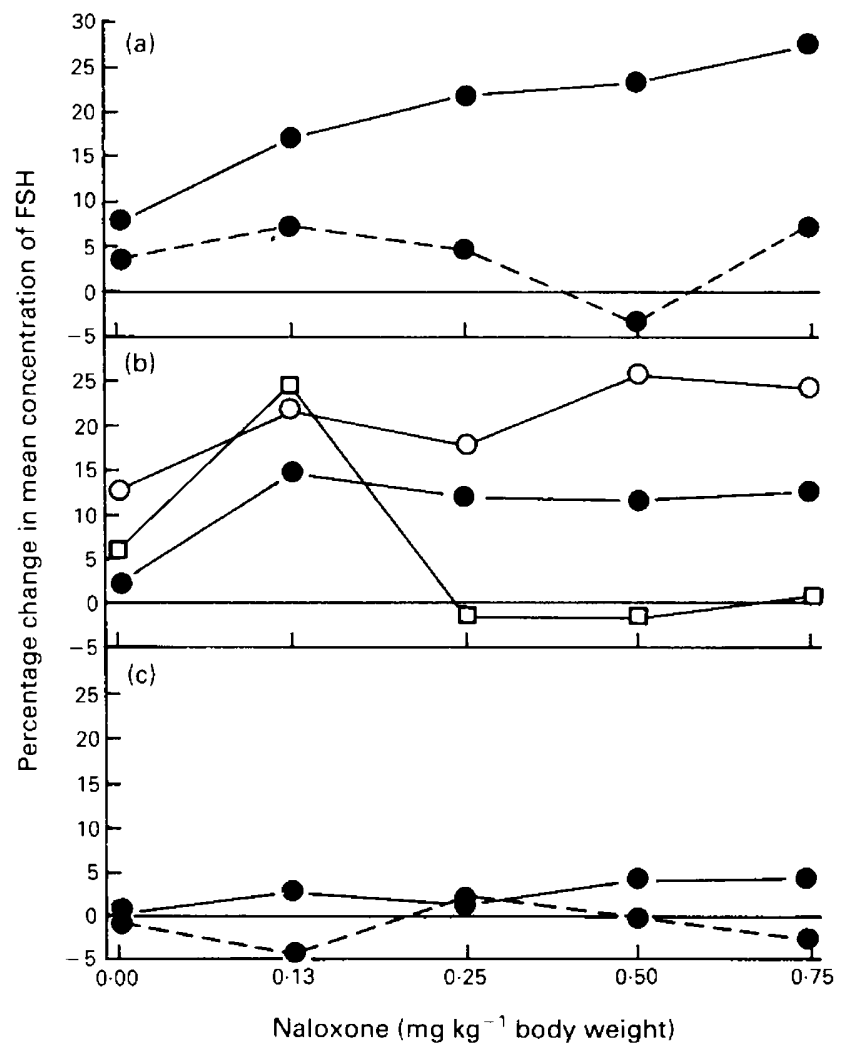

Fig. 4. Percentage increase or decrease in mean concentrations of follicle-stimulating hormone (FSH) after administration of naloxone. Naloxone was administered to sham-implanted ovariectomized heifers (-- ) at (a) 426 and (c) 516 days of age and to ovariectomized heifers treated with oestradiol (- $(-)$ at (a) 426, (b) $447(\bigcirc), 468(\bigcirc), 488$ ( $\square$ ) and (c) 516 days of age. Average age at puberty in intact control heifers was 465 days of age.

Administration of naloxone induced an increase in serum FSH in ovariectomized heifers implanted with oestradiol at 426 days of age $(P<0.01$; Fig. 3), but not at subsequent ages. Similar results were obtained when the data were expressed as percentage deviation in FSH (Fig. 4). The percentage change in the deviation for FSH as a result of naloxone administration was significant in heifers treated with oestradiol only at 426 days of age $(P<0 \cdot 05)$.

\section{Discussion}

Our data on the attenuation of negative feedback by oestradiol on secretion of LH and FSH during the peripubertal period of the heifer confirm previous reports (Schillo et al., 1982; Day et al., 1984; Wolfe et al., 1989). The diminution of oestradiol feedback on gonadotrophin secretion occurred during the time when intact heifers were passing from the pre- to postpubertal state. A similar decline in oestradiol feedback on gonadotrophin secretion has been reported in rats (Docke $e t$ al., 1984a; Docke et al., 1984b) and sheep (Foster \& Ryan, 1979).

Opioid inhibition appeared to require the presence of oestradiol. However, sham-implanted heifers responded to naloxone with an increase in LH three weeks after ovariectomy, although at a lower level than the response in heifers treated with oestradiol. This response was surprising because gonadal steroids should have been cleared from the circulation by three weeks after ovariectomy. Most studies conducted to date have provided data that indicate that inhibition of 
LH by opioids requires the presence of steroids. A response to naloxone was not observed at the end of the study in ovariectomized heifers. Although it is difficult to determine from this study, it is possible that opioids may have a minor inhibitory effect on secretion of $\mathrm{LH}$ through a steroidindependent mechanism that changes with sexual maturation. Steroid-independent opioid inhibition of LH secretion occurs in ewe lambs, but it does not change with sexual maturation (Ebling et al., 1989).

In ovariectomized heifers treated with oestradiol, naloxone administration resulted in an increased secretion of $\mathrm{LH}$ before and after the time when control heifers attained puberty. A time by treatment (response to naloxone) interaction was not observed when the data were expressed as the absolute deviation from the preinjection values. This suggests that opioids do not have a major role in the decline in oestradiol inhibition of gonadotrophin secretion that occurs during the peripubertal period of heifers. However, the overall response of LH to naloxone appeared to decline from the first to fourth blood collection (the only period in which LH did not respond to naloxone). This corresponds to the peripubertal period in control heifers. Interestingly, by the fifth period of blood collection when all control heifers had attained puberty, LH was again responsive to administration of naloxone. Similar data and interpretations have been presented for prepubertal ewe lambs. Administration of multiple injections of naloxone to ovariectomized ewe lambs receiving oestradiol increased both mean concentrations of LH and the frequency of LH pulses (Ebling et al., 1989). However, response to naloxone did not change during sexual maturation in these ewe lambs. In other studies with prepubertal ewe lambs, administration of naloxone increased LH concentration in circulation at 20,25 and 30 weeks of age but had no effect at 5, 10 and 15 weeks of age (Rawlings \& Churchill, 1990). Thus the role of opioids during sexual maturation of ewe lambs is not clear.

A different interpretation is made when the data are expressed as percentage deviation from preinjection concentrations of $\mathrm{LH}$. When data are evaluated in this way a decline in opioid inhibition of $\mathbf{L H}$ secretion is observed across the time course of the study in ovariectomized heifers receiving oestradiol. This occurred during the time that oestradiol inhibition of $\mathrm{LH}$ secretion was abating and suggests that opioids may play a role in oestradiol inhibition of LH secretion during the peripubertal period. This interpretation is supported by data from rats (Ieiri et al., 1979; Bhanot \& Wilkinson, 1983b; Sylvester et al., 1985). An age-related decrease was observed in the ability of a met-enkephalin analogue to inhibit secretion of $\mathbf{L H}$ in immature female rats (Bhanot \& Wilkinson, 1983b). Higher concentrations of this opioid neuropeptide analogue were required to obtain $50 \%$ inhibition of LH as rats neared the time of puberty. A similar result is observed in prepubertal ewe lambs upon close examination of the data (Ebling et al., 1989). Before puberty secretion of LH before naloxone treatment was low, whereas after puberty pre-naloxone secretion of $\mathrm{LH}$ was high, which is similar to data in the present study. Although the absolute change in LH after administration of naloxone did not change during sexual maturation of these ewe lambs, if expressed as percentage deviation, a decline in responsiveness to naloxone would probably have been observed.

We suggest that the percentage deviation data make an alternative and possibly a more meaningful comparison between treatment groups and across time. This is because concentrations of LH before administration of naloxone vary substantially. We have used the percentage deviation analysis to adjust for these differences. Opioid inhibition of $\mathrm{LH}$ occurred during the oestrous cycle of yearling heifers and ewe lambs, but not in mature cows and ewes (Mahmoud et al. 1989; Schall et al., 1991). On the basis of this study it appears that opioid suppression of LH continues to abate after onset of oestrous cycles at puberty. Thus, opioids may have an important role in modulation of LH during the peripubertal period but may continue to modulate LH during the earlier part of the postpubertal period in cows.

The various concentrations of naloxone administered in this study elicited the same response. No consistent pattern of response for LH or FSH was observed after administration of increasing concentrations of naloxone (Figs 1 and 3). In most instances, the $0.13 \mathrm{mg} \mathrm{kg}^{-1}$ dose of naloxone induced a similar response to the $0.75 \mathrm{mg} \mathrm{kg}^{-1}$ dose. If naloxone induced an increase in $\mathrm{LH}$ 
secretion, the magnitude of the increase appeared to be similar to all doses of naloxone administered and across all ages. The results of this study are similar to previous results (Bhanot \& Wilkinson, 1984; Sylvester et al., 1985) in that administration of various concentrations of naloxone to immature female rats resulted in an all or none response. Collectively, these data suggest that even if a broader dose-response curve had been used in the present study a dose-response relationship would not have been detected.

Administration of naloxone resulted in a larger increase in concentrations of LH than of FSH, particularly when percentage deviation in gonadotrophins are examined. This is consistent with previous work in both prepubertal and postpubertal rats (Bhanot \& Wilkinson, 1984; Allen et al., 1988) and during the oestrous cycle in ewes (Currie \& Rawlings, 1987). Administration of naloxone allowed an increase in secretion of $\mathrm{LH}$, but had little or no effect on secretion of FSH. Together these data suggest that different mechanisms may be modulating the secretion of LH and FSH.

In summary, opioid neuropeptides have inhibitory effects on gonadotrophin secretion in heifers before and after puberty. As oestradiol inhibition of gonadotrophin secretion declines opioid inhibition of gonadotrophin secretion may also decline. In conclusion, these data implicate a link between opioid neuropeptides and negative feedback by oestradiol on gonadotrophin secretion during peripuberty in heifers.

We thank L. Rife for her patience in preparation of this manuscript; K. Moline, B. Broweleit and J. Bergman for management of the cattle; K. Pearson and G. Caddy for technical assistance with hormone analysis; J. Reeves and J. Dias for providing LH and FSH antisera, respectively, and L. Reichert, Jr for the purified LH and FSH. This research was supported by USDA CRGO 86-0118 and is published as the Nebraska Agricultural Research Division Journal Series No. 9346.

\section{References}

Acosta, B., Tarnavsky, G.K., Platt, T.E., Hamernik, D.L., Brown, J.L., Schoenemann, H.M. \& Reeves, J.J. (1983) Nursing enhances the negative effect of estrogen on LH release in the cow. Journal of Animal Science 57, 1530-1536.

Adams, T.E., Kinder, J.E., Chakraborty, P.K., Estergreen, V.L. \& Reeves, J.J. (1975) Ewe luteal function influenced by pulsatile administration of synthetic LHRH/FSHRH. Endocrinology 97, 1460-1467.

Allen, L.G., Hahn, E., Caton, D. \& Kalra, S.P. (1988) Evidence that a decrease in opioid tone on proestrus changes the episodic pattern of luteinizing hormone (LH) secretion: implications in the preovulatory $\mathbf{L H}$ hypersecretion. Endocrinology 122, 1004-1013.

Bhanot, R. \& Wilkinson, M. (1983a) Opiatergic control of LH secretion is eliminated by gonadectomy. Endocrinology 112, 399-401.

Bhanot, R. \& Wilkinson, M. (1983b) Opiatergic control of gonadotropin secretion during puberty in the rat: a neurochemical basis for the hypothalamic gonadostat. Endocrinology 113, 596-603.

Bhanot, R. \& Wilkinson, M. (1984) The inhibitory effect of opiates on gonadotropin secretion is dependent upon gonadal steroids. Journal of Endocrinology 102, $133-141$.

Blank, M.S., Panerai, A.E. \& Friesen, H.G. (1979) Opioid peptides modulate luteinizing hormone secretion during sexual maturation. Science 203, 1129-1131.

Currie, W.D. \& Rawlings, N.C. (1987) Naloxone enhances LH but not FSH release during various phases of the estrous cycle in the ewe. Life Science 41, 1207-1214.

Day, M.L., Imakawa, K., Garcia-Winder, M., Zalesky, D.D., Schanbacher, B.D., Kittok, R.J. \& Kinder, J.E. (1984) Endocrine mechanisms of puberty in heifers: estradiol negative feedback regulation of luteinizing hormone secretion. Biology of Reproduction 31, 322-341.

Day, M.L., Imakawa, K., Wolfe, P.L., Kittok, R.J. \& Kinder, J.E. (1987) Endocrine mechanisms of puberty in heifers: role of hypothalamo-pituitary estradiol receptors in the negative feedback of estradiol on luteinizing hormone secretion. Biology of Reproduction 37, 1054-1065.

Deaver, D.R., Glass, J.D., Greiger, D.M. \& Reeves, J.J. (1988) Effects of estradiol on secretion of LH, hypothalamic function and testicular development in bull calves. Domestic Animal Endocrinology 5, 307-316.

Docke, F., Rohde, W., Gerber, P. \& Dorner, G. (1984a) Evidence that desensitization to the negative estrogen feedback is a prepubertal and not a postpubertal event in female rats. Experimental Clinical Endocrinology 84, $1-6$.

Docke, F., Rohda, W., Stahl, F., Smollich, A. \& Dorner, G. (1984b) Serum levels of FSH, LH, and estradiol$17 \beta$ in female rats around the time of puberty onset. Experimental Clinical Endocrinology 83, 6-13.

Ebling, F.J.P., Schwartz, M.L. \& Foster, D.L. (1989) Endogenous opioid regulation of pulsatile luteinizing hormone secretion during sexual maturation in the female sheep. Endocrinology 125, 369-383. 
Foster, D.L. \& Ryan, K.D. (1979) Endocrine mechanisms governing transition into adulthood: a marked decrease in inhibitory feedback action of estradiol on tonic secretion of luteinizing hormone in the lamb during puberty. Endocrinology 105, 896-904.

leiri, T., Chen, H.T. \& Meites, J. (1979) Effects of morphine and naloxone on serum levels of luteinizing hormone and prolactin in prepubertal male and female rats. Neuroendocrinology 29, 288-292.

Mahmoud, A.I., Thompson, F.N., Peck, D.D., Mizinga, K.M., Leshin, L.S., Rund, L.A., Stuedmann, J.A. \& Kiser, T.E. (1989) Difference in luteinizing hormone response to an opioid antagonist in heifers and cows. Biology of Reproduction 41, 431-437.

Malven, P.V., Bossut, D.F.B. \& Dickman, M.A. (1984) Effects of naloxone and electroacupuncture treatment on plasma concentrations of LH in sheep. Journal of Endocrinology 101, 75-80.

Mathews, M.V. \& Murdoch, W.J. (1984) Increased secretion of luteinizing hormone in prepubertal ewes treated with an antagonist of opiates. Domestic Animal Endocrinology 1, 167-173.

Rawlings, N.C. \& Churchill, I.J. (1990) Effect of naloxone on gonadotrophin secretion at various stages of development in the ewe lamb. Journal of Reproduction and Fertility 89, 503-509.

SAS Users Guide (1985) Cary, NC, SAS Institute, Inc.

Schall, R.E., Ebling, F.J.P., Karsch, F.J. \& Foster, D.L. (1991) Postpubertal maturation of endogenous opioid regulation of luteinizing hormone secretion in the female sheep. Biology of Reproduction 44, $760-768$.

Schams, D., Schallenberger, E., Gombe, S. \& Karg, H. (1981) Endocrine patterns associated with puberty in male and female cattle. Journal of Reproduction and Fertility 30, 103-110.

Schillo, K.K., Dierschke, D.J. \& Hauser, E.R. (1982) Regulation of luteinizing hormone secretion in prepubertal heifers: increased threshold to negative feedback action of estradiol. Journal of Animal Science 54, 325-336.

Sylvester, P.W., Sarkar, D.K., Briski, K.P. \& Meites, J. (1985) Relation of gonadal hormones to differential LH response to naloxone in prepubertal male and female rats. Neuroendocrinology 40, 165-170.

Whisnant, C.S. \& Goodman, R.L. (1988) Effects of an opioid antagonist on pulsatile luteinizing hormone secretion in the ewe vary with changes in steroid negative feedback. Biology of Reproduction 39, 1032-1038.

Wolfe, M. W., Stumpf, T.T., Roberson, M.S., Wolfe, P.L., Kittok, R.J. \& Kinder, J.E. (1989) Estradiol influences on pattern of gonadotropin secretion in bovine males during the period of changed responses to estradiol feedback in age-matched females. Biology of Reproduction 41, 626-634.

Received 29 July 1991 